\title{
Middle East Respiratory Syndrome Coronavirus Seropositivity in Camel Handlers and Their Families, Pakistan
}

\section{Jian Zheng, ${ }^{1}$ Sohail Hassan, ${ }^{1}$ Abdulaziz N. Alagaili, Abeer N. Alshukairi, Nabil M.S. Amor, Nadia Mukhtar, Iqra Maleeha Nazeer, Zarfishan Tahir, Nadeem Akhter, Stanley PerIman, Tahir Yaqub}

A high percentage of camel handlers in Saudi Arabia are seropositive for Middle East respiratory syndrome coronavirus. We found that $12 / 100$ camel handlers and their family members in Pakistan, a country with extensive camel MERS-CoV infection, were seropositive, indicating that MERS-CoV infection of these populations extends beyond the Arabian Peninsula.

$\mathrm{M}$ iddle East respiratory syndrome (MERS) coronavirus (MERS-CoV), identified in 2012, causes a highly lethal pneumonia with a $34.5 \%$ mortality rate (https://www. who.int/emergencies/mers-cov). As of July 31, 2019, a total of 2,458 cases and 848 deaths have been reported to the World Health Organization, with all cases in the Middle East or in travelers from this region or their contacts (1). MERS cases fall into 2 categories, primary and secondary. Secondary cases, which result most commonly from human-to-human transmission in hospitals, were most prominent during the early years of the outbreak. However, as stringent infection control measures have been followed more closely, a greater proportion of cases are classified as primary. Camels are believed to be the zoonotic source for primary infections, but a large proportion of patients describe no camel contact, raising the question of how they acquired the disease (2).

To determine the source of the infection, several studies have focused on a potential role in transmission for

Author affiliations: University of lowa, lowa City, lowa, USA (J. Zheng, S. Perlman); University of Veterinary and Animal Sciences, Lahore, Pakistan (S. Hassan, I.M. Nazeer, T. Yaqub); King Saud University, Riyadh, Saudi Arabia (A.N. Alagaili, N.M.S. Amor); King Faisal Specialist Hospital and Research Centre, Jeddah, Saudi Arabia (A.N. Alshukairi); Government of Punjab, Lahore (N. Mukhtar, Z. Tahir, N. Akhter); The First Affiliated Hospital of Guangzhou Medical University, Guangzhou, China (S. Perlman)

DOI: https://doi.org/10.3201/eid2512.191169 camel handlers. These reports indicate that the percentage of MERS-CoV-immune camel handlers is much greater than in the general population of Saudi Arabia, the country with the largest number of MERS cases. These studies have reported that $3 \%-67 \%$ of camel handlers in this country are MERS-CoV exposed, compared with $0.15 \%$ of the general population (3-5). In Saudi Arabia, much of camel farming is labor intensive, and many camel owners hire camel handlers, generally from outside of the country, to tend to them (6). To determine the generalizability of these observations, we tested blood samples from 100 camel handlers and their families in the Cholistan desert in Punjab, Pakistan, a country with no reported human MERS (7).

\section{The Study}

We chose Cholistan as the study site because it is the most important region of Pakistan for the camel industry, and handlers and their families are in close contact with dromedaries. We engaged study participants in the Bahawalnagar and Bahawalpur districts, located in southern Punjab Province, Pakistan. The Institutional Ethical Review Board (IERB) of the Institute of Public Health, Government of Punjab, Lahore, Pakistan, approved the study. We obtained written informed consent from all study participants.

Camel handlers in Cholistan differ from those in Saudi Arabia in that they own their camels, along with cows, goats, and sheep, and they and their families take care of these animals. Both men and women are responsible for grazing, feeding, milking, and waste disposal. In addition, they live in close proximity to camels and share similar water sources $(8-10)$. Camel handlers in Cholistan are either nomadic, seminomadic, or sedentary, with varying degrees of exposure to camels. Nomads live with their camels in the desert and migrate throughout Cholistan, whereas seminomads tend to live at a base camp and migrate depending on availability of fodder and water. Nomadic camel handlers and their families have the highest exposure to camels, whereas sedentary ones have the least exposure.

During 2017-2018, we obtained blood samples from 100 participants from nomadic, seminomadic, and sedentary populations. The age range was $8-76$ years (average

${ }^{1}$ These first authors contributed equally to this article. 
Table 1. Characteristics of participants in study of Middle East respiratory syndrome coronavirus seropositivity in camel handlers and their families, Pakistan

\begin{tabular}{lc}
\hline Characteristic & $\begin{array}{c}\text { No. }(\%) \\
\text { participants }\end{array}$ \\
\hline Lifestyle & \\
$\quad$ Sedentary & $10(10)$ \\
Seminomadic & $64(64)$ \\
$\quad$ Nomadic & $26(26)$ \\
\hline Concurrent conditions & $21(21)$ \\
Consumption of unpasteurized camel milk & $98(98)$ \\
Tobacco use & $38(38)$ \\
\hline
\end{tabular}

30.1 years). We obtained demographic and clinical information at sampling by written questionnaire, including participant age, lifestyle (nomadic, seminomadic, sedentary), role in family (husband, wife, child, etc.), underlying medical conditions, numbers of camels owned, history of tobacco use (smoking or chewing), and consumption of camel products (milk) (Table 1; Appendix Table, https:// wwwnc.cdc.gov/EID/article/25/12/19-1169-App1.pdf). We transported samples to the microbiology department at the University of Veterinary and Animal Sciences (Lahore, Punjab, Pakistan). We prepared serum samples, stored them at $-80^{\circ} \mathrm{C}$, and shipped them to the University of Iowa (Iowa City, Iowa, USA) for analysis.

We tested all the samples for MERS-CoV-specific antibodies by ELISA and 50\% reduction plaque-reduction neutralization test $\left(\mathrm{PRNT}_{50}\right)$. Of 91 participants examined by a commercially available ELISA, 49 were positive for MERS-CoV-specific antibody. Twelve had $\mathrm{PRNT}_{50}$ titers $>1: 20$ and were considered positive; of these, 5 were also positive by ELISA. In addition, 10/12 were positive by immunofluorescence assay. Of the $12 \mathrm{PRNT}_{50}$-positive participants, 3 were women and 1 was an 8 -year-old child (Table 2).
All but 2 of the study participants were exposed to camels. There was no significant correlation $(p>0.5)$ between MERS-CoV seropositivity and lifestyle, presence of concurrent conditions, drinking unpasteurized camel milk, or tobacco use, with the caveat that the sample size was small.

\section{Conclusions}

In general, nomads had the most and sedentary populations had the least camel contact, although nearly all family members were exposed to and took care of camels. Of 100 participants, we identified 12 who were MERS-CoV seropositive, as measured by the presence of $\mathrm{PRNT}_{50}$ antibody. Of note, several $\mathrm{PRNT}_{50}$-positive samples were negative by ELISA, but most were positive by immunofluorescence assay. This lack of concordance between ELISA and $\mathrm{PRNT}_{50}$ titers was observed previously $(3,11)$ and may reflect lower sensitivity of the commercial ELISA kit (12). Other coronaviruses circulate in camel populations (13), and it is conceivable that the high rate of ELISA seropositivity resulted from immune responses to other, possibly MERSlike, coronaviruses present in Pakistan. Thus, it will be important to assess camel (and human) populations for other coronaviruses that might elicit a cross-reactive response.

The mechanism of MERS-CoV transmission from camels to humans in Pakistan is not established, but most camel handlers and their families drink fresh camel milk, obtained after young camels have finished nursing. Juvenile camels demonstrate the highest rate of seroconversion and of MERS-CoV positivity $(6,14)$, so it is possible that drinking fresh milk is a source of infection. In this region of Pakistan, camel handlers and their families also share water sources with camels, which probably

\begin{tabular}{|c|c|c|c|c|c|c|c|c|c|}
\hline $\begin{array}{l}\text { Patient } \\
\text { no. }\end{array}$ & $\begin{array}{c}\text { Family } \\
\text { no. }\end{array}$ & $\begin{array}{l}\text { Age, yl } \\
\text { sex }\end{array}$ & Camel contact $†$ & Smoking & $\begin{array}{l}\text { Concurrent } \\
\text { conditions }\end{array}$ & Lifestyle & $\mathrm{PRNT}_{50}$ & $\begin{array}{c}\text { ELISA result/ } \\
\text { valuef }\end{array}$ & $\begin{array}{l}\text { IFA result/ } \\
\text { titer§ }\end{array}$ \\
\hline SH94 & F2 & $20 / \mathrm{M}$ & Direct/daily & Yes & None & Nomadic & 211 & $-/ 0.78$ & $+/ 1: 80$ \\
\hline SH85 & $\mathrm{F} 2$ & $21 / \mathrm{M}$ & Direct/daily & Yes & None & Nomadic & 32 & $+/ 1.51$ & $+/ 1: 40$ \\
\hline SH100 & F1 & $8 / \mathrm{M}$ & Direct/daily & No & None & Nomadic & 72 & $-/ 0.64$ & $+/ 1: 40$ \\
\hline SH71 & F9 & $35 / F$ & Indirect & No & $\begin{array}{l}\mathrm{HPT} \text {, renal and } \\
\text { respiratory disease }\end{array}$ & Seminomadic & 33 & $\begin{array}{c}\text { Borderline/ } \\
0.99\end{array}$ & $+/ 1: 20$ \\
\hline SH74 & F9 & $40 / F$ & Indirect & No & HPT & Seminomadic & 40 & $+/ 2.18$ & $+/ 1: 80$ \\
\hline SH63 & F13 & $35 / F$ & Direct/monthly & No & None & Seminomadic & 27 & $\begin{array}{c}\text { Borderline/ } \\
0.92\end{array}$ & $+/ 1: 10$ \\
\hline SH57 & F14 & 20/M & Direct & No & None & Seminomadic & 51 & $+/ 3.11$ & $+/ 1: 80$ \\
\hline SH58 & F16 & 28/M & Direct & Yes & None & Seminomadic & 68 & $+/ 1.74$ & $+/ 1: 160$ \\
\hline $\mathrm{SH} 21$ & None & $17 / \mathrm{M}$ & Direct/seasonal & Yes & None & Seminomadic & 80 & -10.36 & $-\mid<1: 10$ \\
\hline SH65 & None & 20/M & D/daily & No & None & Seminomadic & 65 & $+/ 1.13$ & $+/ 1: 80$ \\
\hline $\mathrm{SH} 43$ & None & $34 / \mathrm{M}$ & Direct & No & None & Sedentary & 1,600 & $-/ 0.76$ & $+/ 1: 160$ \\
\hline $\mathrm{SH} 44$ & None & 40/M & Direct & Yes & None & Sedentary & 89 & -10.48 & $-\mid<1: 10$ \\
\hline \multicolumn{10}{|c|}{$\begin{array}{l}{ }^{*} \text { All } 12 \text { patients tested positive by PRNT } 50 \text {. IFA, immunofluorescence assay; HPT, hypertension; PRNT } 50,50 \% \text { reduction plaque reduction neutralization } \\
\text { assay. } \\
\text { †Direct indicates camel herders with direct camel contact but extent of exposure is not known; direct/daily, camel herders with daily direct camel contact; } \\
\text { direct/monthly, camel herders with monthly direct camel contact; direct/seasonal, camel herders with seasonal direct camel contact; indirect, family } \\
\text { members of camel herders. } \\
\text { †Positive result is }>1.1 \text {; borderline, } 0.8-1.1 \text {; negative, }<0.8 \text {, as defined by the test manufacturer. } \\
\S N \text { egative test result is }<1: 10, \text { as defined by the test manufacturer. }\end{array}$} \\
\hline
\end{tabular}


contributes to virus transmission. Zohaib et al. identified a $75.6 \%$ MERS seroprevalence in camels throughout Pakistan, but $0 \%$ seropositivity in humans, including some with camel contact (7).

Medical services in Cholistan and adjacent areas are limited, making MERS diagnosis and transmission studies difficult. Our findings show a need for additional studies to confirm the absence of clinically apparent MERS in this region and to determine whether epidemiologic, technical, or other factors caused differences in seropositivity between our study and that of Zohaib et al.

Our study, by demonstrating a low but detectable rate of MERS-CoV seropositivity in camel handlers and their families, indicates that this population could contribute to MERS$\mathrm{CoV}$ transmission to the broader community in Pakistan. We previously showed that measurement of $\mathrm{T}$ cell responses identified additional MERS-CoV-immune persons $(3,11)$, suggesting that our results may underestimate the prevalence of MERS-CoV infection. Our results also illustrate the importance of educating camel herders and their families about proper infection control measures, including handwashing, to diminish the likelihood of MERS-CoV transmission.

\section{Acknowledgments}

We thank Aftab Ahmad Anjum and Ali Raza Abbasi for their assistance during field sampling in the Cholistan desert.

This study was supported in part by the Vice Deanship of Research Chairs, Deanship of Scientific Research of the King Saud University, Riyadh, Saudi Arabia. S.P. was supported in part by grants from the US National Institutes of Health (RO1 AI129269 and PO1 AI060699).

\section{About the Author}

Dr. Zheng is a postdoctoral researcher in the Department of Microbiology and Immunology, University of Iowa. His research interests are in respiratory viruses, such as human coronaviruses and influenza viruses. Dr. Hassan is a lecturer in microbiology, University of Veterinary and Animal Sciences, Lahore, Pakistan. His primary research interests are emerging viral infections and zoonoses at the animal-human interface.

\section{References}

1. Hui DS, Azhar EI, Kim YJ, Memish ZA, Oh MD, Zumla A. Middle East respiratory syndrome coronavirus: risk factors and determinants of primary, household, and nosocomial transmission. Lancet Infect Dis. 2018;18:e217-27. https://doi.org/10.1016/ S1473-3099(18)30127-0
2. Conzade R, Grant R, Malik MR, Elkholy A, Elhakim M, Samhouri D, et al. Reported direct and indirect contact with dromedary camels among laboratory-confirmed MERS-CoV cases. Viruses. 2018;10:425. https://doi.org/10.3390/v10080425

3. Alshukairi AN, Zheng J, Zhao J, Nehdi A, Baharoon SA, Layqah L, et al. High prevalence of MERS-CoV infection in camel workers in Saudi Arabia. MBio. 2018;9:e01985-18. 10.1128/mBio.01985-18 https://doi.org/10.1128/mBio.01985-18

4. Khudhair A, Killerby ME, Al Mulla M, Abou Elkheir K, Ternanni W, Bandar Z, et al. Risk factors for MERS-CoV seropositivity among animal market and slaughterhouse workers, Abu Dhabi, United Arab Emirates, 2014-2017. Emerg Infect Dis. 2019;25:927-35. https://doi.org/10.3201/eid2505.181728

5. Müller MA, Meyer B, Corman VM, Al-Masri M, Turkestani A, Ritz D, et al. Presence of Middle East respiratory syndrome coronavirus antibodies in Saudi Arabia: a nationwide, cross-sectional, serological study. Lancet Infect Dis. 2015;15:55964. https://doi.org/10.1016/S1473-3099(15)70090-3

6. Hemida MG, Elmoslemany A, Al-Hizab F, Alnaeem A, Almathen F, Faye B, et al. Dromedary camels and the transmission of Middle East respiratory syndrome coronavirus (MERS-CoV). Transbound Emerg Dis. 2017;64:344-53. https://doi.org/10.1111/ tbed.12401

7. Zohaib A, Saqib M, Athar MA, Chen J, Sial AU, Khan S, et al. Countrywide survey for MERS-coronavirus antibodies in dromedaries and humans in Pakistan. Virol Sin. 2018;33:410-7. https://doi.org/10.1007/s12250-018-0051-0

8. Ali I, Chaudhry MS, Farooq U. Camel rearing in Cholistan Desert of Pakistan. Pak Vet J. 2009;29:85-92.

9. Khan AA, Khan K. Women's role in livestock economy of Cholistan Desert, Pakistan. Global Journal of Human-Social Science: E Economics. 2015;15:29-39 [cited 2019 Oct 18]. https://globaljournals.org/GJHSS_Volume15/4-Womens-Role-inLivestock-Economy.pdf

10. Amin H, Ali T, Ahmad M, Zafar M. Gender and development: roles of rural women in livestock production in Pakistan. Pak J Agric Sci. 2010;47:32-6.

11. Zhao J, Alshukairi AN, Baharoon SA, Ahmed WA, Bokhari AA, Nehdi AM, et al. Recovery from the Middle East respiratory syndrome is associated with antibody and T-cell responses. Sci Immunol. 2017; eaan5393. https://doi.org/10.1126/sciimmunol.aan5393

12. Okba NMA, Raj VS, Widjaja I, GeurtsvanKessel CH, de Bruin E, Chandler FD, et al. Sensitive and specific detection of low-level antibody responses in mild Middle East respiratory syndrome coronavirus infections. Emerg Infect Dis. 2019;25:1868-77. https://doi.org/10.3201/eid2510.190051

13. Sabir JSM, Lam TT-Y, Ahmed MMM, Li L, Shen Y, Abo-Aba SEM, et al. Co-circulation of three camel coronavirus species and recombination of MERS-CoVs in Saudi Arabia. Science. 2016;351:81-4. https://doi.org/10.1126/science.aac8608

14. Wernery U, Lau SK, Woo PC. Middle East respiratory syndrome (MERS) coronavirus and dromedaries. Vet J. 2017;220:75-9. https://doi.org/10.1016/j.tvj1.2016.12.020

Address for correspondence: Stanley Perlman, University of Iowa, Department of Microbiology and Immunology, 51 Newton Rd, Iowa City, IA 52242, USA; email: stanley-perlman@uiowa.edu; Sohail Hassan, University of Veterinary and Animal Sciences, Department of Microbiology, Lahore 54000, Pakistan; email: sohail.hassan@uvas.edu.pk 